\title{
Evasão escolar precoce no ensino superior a distância: Uma análise segundo os dados do curso de licenciatura em letras no IFPB
}

\author{
Early school dropout in distance higher education: An analysis according to data from the degree \\ in letters course at IFPB
}

Abandono escolar prematuro en la educación superior a distancia: Un análisis según datos de la licenciatura en idiomas de la IFPB

Recebido: 16/06/2021 | Revisado: 21/06/2021 | Aceito: 22/06/2021 | Publicado: 29/06/2021

João Ricardo Freire de Melo
https://orcid.org/0000-0001-8407-1188
E-mail: joao.melo@ifpb.edu.br
Instituto Federal de Educação, Ciência e Tecnologia da Paraía, Brasil
Ana Karoliny de Assis Medeiros
https://orcid.org/0000-0002-7696-0388
Instituto Federal de Educação, Ciência e Tecnologia da Paraíba, Brasil
E-mail: anakarolinyjs@gmail.com

\section{Resumo}

A Evasão Escolar Precoce em curso de graduação na modalidade EaD trata-se de uma particularidade do tipo de evasão relacionada intrinsicamente ao momento da saída desse aluno da unidade educacional. Existe pouco material na literatura científica que discuta esse fenômeno acadêmico e uma real solução para a problemática. Metodologicamente adotadamos os pressupostos de uma abordagem quali/quanti, configurando-se numa pesquisa de natureza aplicada com objetivo explicativo. Com procedimentos de coleta de dados realizados via pesquisa bibliográfica, documental e de estudo de caso. Analisamos o curso de licenciatura em Letras à distância no IFPB com discentes ingressantes no primeiro semestre do ano letivo de 2019. Definir políticas de retenção, analisar as probabilidades individuais de abandono desde o ingresso do aluno e redefinir práticas pedagógicas são apontamentos que podem direcionar os atores educacionais a estabelecer condutas que reverberem na permanência desse aluno na escola.

Palavras-chave: Evasão Escola Precoce; Educação a Distância; Curso Superior; Ensino.

\begin{abstract}
Early School Evasion in an undergraduate course in distance education is a peculiarity of the type of dropout that is intrinsically related to the moment when this student leaves the educational unit. There is little material in the scientific literature to discuss this academic phenomenon and a real solution to the problem. Methodologically, we adopted the assumptions of a quali / quanti approach, configuring an applied nature research with an explanatory objective. With data collection procedures carried out via bibliographic, documentary and case study research. We analyzed the distance learning degree course at the IFPB with incoming students in the first semester of the 2019 academic year. Defining retention policies, analyzing the individual probabilities of dropping out since the student's admission and redefining pedagogical practices are notes that can direct the actors educational institutions to establish conducts that reverberate in the permanence of this student in school.
\end{abstract}

Keywords: Evasion Early School; Distance Education; Higher Education; Teaching.

\section{Resumen}

La deserción escolar temprana en un curso de $\mathrm{EaD}$ es una particularidad del tipo de deserción intrínsecamente relacionada con el momento en que este alumno abandona la unidad educativa. Hay poco material en la literatura científica que discuta este fenómeno académico y una solución real al problema. Metodológicamente, adoptamos los supuestos de un enfoque cuali / cuanti, configurando una investigación aplicada con un propósito explicativo. Con procedimientos de recolección de datos realizados a través de investigaciones bibliográficas, documentales y de estudios de casos. Analizamos el curso de Licenciatura en Idiomas a distancia en la IFPB con alumnos que ingresan al primer semestre del curso 2019. Definir políticas de retención, analizar las probabilidades individuales de deserción desde la admisión de los estudiantes y redefinir las prácticas pedagógicas son apuntes que pueden orientar a los actores hacia Establecer conductas que repercutan en la permanencia de este alumno en la escuela.

Palabras clave: Abandono escolar temprano, Educación a distancia, Educación superior; Ensenãnza. 


\section{Introdução}

A evasão escolar representa um fenômeno complexo, com múltiplas e particulares variáveis. Causa prejuízos que afetam os indivíduos, as organizações e a própria sociedade como um todo. Esses prejuízos dão origem a efeitos individuais e sociais, principalmente no campo educacional com prejuízos que se relacionam, de forma imbricada, nos processos de planejamento institucional (Prestes \& Fialho, 2018).

A evasão significa a não finalização de uma unidade educacional (curso, treinamento ou outra modalidade instrucional) que conduza o alunado a um conhecimento especializado. Utilizando a definição empregada no Ministério da Educação, evasão seria a saída definitiva do aluno de seu curso de origem, sem concluí-lo (Brasil, 2016). Esse fenômeno devese a fatores individuais, internos ou externos à instituição, sendo contabilizada pela diferença entre o número de matriculados e concluintes em seu ciclo acadêmico. Fato complexo, comum às instituições de ensino no mundo contemporâneo.

A própria expansão do ensino superior ampliou a visibilidade da evasão e os problemas decorrentes, propiciando mais estudos sobre os possíveis motivos causadores deste fenômeno, centrados nas condições acadêmicas, pessoais e sociais dos estudantes. Considerando as escassas políticas efetivas de combate à evasão nos cursos de EaD, e, com o crescimento célere desta modalidade de ensino, aumenta também, significativamente, a evasão escolar.

Segundo os referenciais do INEP (2018), quando da divulgação dos principais resultados do Censo da Educação Superior em 2017, expõe o seguinte. Em 2007, a modalidade a distância representava 7,0\% das matrículas de graduação. Nos últimos 10 anos, a educação a distância vem aumentando sua participação na educação superior. Em 2017, a EaD aumentou 17,6\% e já atende mais de 1,7 milhão de alunos, o que representa uma participação de 21,2\% dos alunos de graduação no país. A modalidade presencial apresenta o $2^{\circ}$ ano de queda no número de matrículas (INEP, 2018, p.26).

No caso específico da educação a distância, o problema da evasão ainda é pouco trabalhado, e muitas vezes, discutido de forma preambular quando se trata do combate à evasão de alunos (Bittencourt \& Mercado, 2014). Embora a literatura científica demonstre grandes esforços para analisar esse fenômeno (Tinto, 1975; Braga, et al., 2003; Bittencourt \& Mercado, 2014; Carneiro, et al., 2015; Cornelio, et al., 2016; Carvalho, et al., 2018; Queiroga, et al., 2018; Habowski, et al., 2020; Kemper, et al., 2020), existe pouco material que discuta uma real solução para a problemática.

Tenta-se desenvolver modelos explicativos que deem conta do processo de evasão escolar. Desde estudos clássicos como o de Tinto (1975) que propõe um modelo teórico longitudinal do processo de abandono em que argumenta que o processo de evasão das instituições de ensino superior pode ser visto como um processo longitudinal de interações entre o indivíduo e os sistemas acadêmico e social durante o qual as experiências de uma pessoa naqueles sistemas (medidos por sua integração normativa e estrutural) modificam continuamente seu objetivo e compromissos institucionais de maneiras que levam à persistência e / ou a várias formas de abandono escolar. Até estudos mais recentes, como os de Kemper, Vorhoff e Wigger (2020) que propõem modelos de abordagens de aprendizado de máquina para prever o abandono escolar. Utiliza para isso métodos computacionais fundamentados em técnicas estatísticas de regressão logística e árvores de decisão.

Nesse estudo, interessa-nos discutir a Evasão Escolar Precoce (EEP) em curso de graduação na modalidade EaD. Trata-se de uma particularidade do tipo de evasão relacionada intrinsicamente ao momento da saída desse aluno da unidade educacional. Tomamos como base que a EEP ocorre quando o aluno não finaliza sua unidade educacional, neste caso, o curso superior, e sua saída se dá entre o momento do seu ingresso até o decorrer de um terço destinado ao cumprimento do prazo total ou da carga horária do referido curso. Cumpre-nos também situar que esse tipo de evasão se refere a saída voluntária do aluno da instituição de ensino. Para Branco, Conte e Habowski (2020), dos alunos que desistem dos cursos de graduação na modalidade $\mathrm{EaD}, 85 \%$ evadem ainda no início do curso.

Diante desse cenário, faz-se necessário (re)pensar formas que contribuam, substancialmente, para diagnosticar as 
causas e subsidiar estratégias eficazes com vistas a mitigar a evasão.

\subsection{Fatores da evasão escolar precoce em EaD}

Nesse cenário, tomamos por base que é atribuição basal da gestão escolar, nos diferentes subsistemas educacionais, implantar estratégias de monitoramento e de prevenção, capazes de propiciar a permanência do alunado matriculado e a conclusão do curso. O planejamento estratégico e a autoavaliação tornam-se, portanto, elementos fundantes na dinâmica educacional, uma vez que tanto o planejamento como a avaliação representam oportunidades para o estabelecimento de objetivos e linhas de ação para as instituições de ensino (Lima, et al., 2020). No esteio desta discussão sobre planejamento estratégico, Bittencourt e Mercado (2014) elencam diversos fatores categorizados em causas endógenas e exógenas que provocam a evasão na educação superior à distância.

Quadro 1. Principais fatores que causam evasão na educação superior à distância.

\begin{tabular}{|c|c|c|}
\hline \multirow{27}{*}{ Endógenas } & \multirow{5}{*}{$\begin{array}{l}\text { Atitude } \\
\text { Comportamental }\end{array}$} & Didática dos professores \\
\hline & & Orientação da coordenação do curso \\
\hline & & Motivação e incentivo por parte do tutor \\
\hline & & Insatisfação com o tutor \\
\hline & & Contato com os professores \\
\hline & \multirow{7}{*}{$\begin{array}{l}\text { Motivos } \\
\text { Institucionais }\end{array}$} & Ausência de tutores nos pólos \\
\hline & & Acesso a bibliotecas \\
\hline & & Estrutura dos pólos de ensino \\
\hline & & Estrutura dos laboratórios de informática \\
\hline & & Interatividade no AVA \\
\hline & & Meios de comunicação oferecidos \\
\hline & & Tecnologia Inadequada \\
\hline & \multirow{15}{*}{$\begin{array}{l}\text { Requisitos didático- } \\
\text { pedagógicos }\end{array}$} & Carga horária curricular do curso \\
\hline & & Relação do currículo com o mercado \\
\hline & & Critérios de avaliação do aluno \\
\hline & & Associação entre teoria e prática \\
\hline & & Relação entre os conteúdos das disciplinas \\
\hline & & Encontros presenciais \\
\hline & & Complexidade das atividades \\
\hline & & Contato entre colegas de curso \\
\hline & & Reprovação em mais de duas disciplinas no semestre \\
\hline & & Prazos de entrega das atividades \\
\hline & & Avaliação dos exercícios \\
\hline & & Avaliação das provas \\
\hline & & Material didático oferecido \\
\hline & & Qualidade do curso \\
\hline & & Falha na elaboração do curso \\
\hline
\end{tabular}




\begin{tabular}{|c|c|c|}
\hline \multirow{23}{*}{$\begin{array}{l}\text { Causas } \\
\text { Exógenas }\end{array}$} & \multirow{8}{*}{$\begin{array}{l}\text { Sócio-político- } \\
\text { econômicos }\end{array}$} & Apoio da instituição que trabalha \\
\hline & & Valorização do diploma no mercado \\
\hline & & Tempo para estudar \\
\hline & & Carga horária semanal de trabalho \\
\hline & & Deslocamento até o pólo de ensino \\
\hline & & Dificuldades de acesso a internet \\
\hline & & Entendimento das matérias \\
\hline & & Adequação do conteúdo com o trabalho \\
\hline & \multirow{6}{*}{ Vocação pessoal } & Aptidão para a profissão \\
\hline & & Possuir outro curso superior \\
\hline & & Adaptação ao sistema universitário \\
\hline & & Mudança de interesse pessoal ou profissional \\
\hline & & Estar cursando paralelamente outro curso \\
\hline & & Desconhecimento prévio a respeito do curso \\
\hline & \multirow{4}{*}{$\begin{array}{l}\text { Características } \\
\text { individuais }\end{array}$} & Problemas de saúde \\
\hline & & Atendimento do curso às expectativas prévias \\
\hline & & Dificuldade de assimilação da cultura da EaD \\
\hline & & Falta de habilidade para usar as TIC \\
\hline & \multirow{5}{*}{ Conjunturais } & Problemas financeiros \\
\hline & & Influência familiar \\
\hline & & Mudança de domicílio \\
\hline & & Mudança de estado civil \\
\hline & & Responsabilidade econômica no sustento da família \\
\hline
\end{tabular}

Fonte: Adaptado de (Bittencourt \& Mercado, 2014, p. 475)

Parece-nos que os fatores elencados pelos autores têm um cunho mais geral e podem ser vistos em tantas outras unidades educacionais. Dentro dos fatores elencados pelos autores, nos deteremos, neste trabalho, num recorte específico de alguns dados dentro das causas exógenas que podem ser diagnosticadas ainda no período de ingresso do estudante. Características essas que sejam mais suscetíveis na análise do fenômeno da EEP. Dados como sexo, idade, estado civil, etnia, ano de conclusão do ensino médio, zona e local de residência, podem dar indícios de grupos mais vulneráveis ao abandono. Ter a posse desses dados e analisá-los, sob o prisma da EPP, pode ser um diferencial que ajude a fomentar políticas de permanência em cursos superiores de EaD. Cumpre-nos analisar, portanto, o perfil dos alunos ingressantes e, destes, aqueles que passam pelo processo de EEP no curso superior de Letras EaD do Instituto Federal da Paraíba.

\section{Metodologia}

O objetivo desta pesquisa é analisar a evasão precoce no curso de Licenciatura em Letras na modalidade à distância do IFPB.

Para alcançar tal objetivo, a metodologia adotada nesta pesquisa fundamenta-se nos pressupostos de uma abordagem qualitativa e quantitativa, configurando-se numa pesquisa de natureza aplicada com objetivo explicativo (Koche, 2011). Com procedimentos de coleta de dados realizados via pesquisa bibliográfica, documental e de estudo de caso (Ludke, Andre; 2013). 
Analisamos a evasão escolar precoce no curso de licenciatura em Letras à distância no IFPB com discentes ingressantes no primeiro semestre do ano letivo de 2019. A referida coleta foi realizada durante o período de dezembro de 2020 a janeiro de 2021. Foi criado um banco de dados utilizando o software Microsoft Excel®.

O procedimento de coleta de dados foi realizado via buscas ao Sistema Unificado de Administração Pública (SUAP) sistema eletrônico utilizado no âmbito do Instituto Federal da Paraíba para a gestão de processos acadêmicos e administrativos. Representa uma ferramenta amplamente utilizada em vários órgãos da Rede Federal de Ensino e possibilita a execução de atividades que envolvam as rotinas de trabalho das áreas administrativas e acadêmicas. Realizamos a referida busca utilizando como parâmetros: ano de ingresso (2019), período de ingresso (1) e curso (64 - Licenciatura em Letras à Distância com Habilitação em Língua Portuguesa - João Pessoa (CAMPUS JOÃO PESSOA).

Cabe frisar que, ao investigar a evasão escolar precoce, nos detivemos apenas a parâmetros assinalados desde a matrícula do discente na instituição. Portanto, dados sobre notas e avaliações desses estudantes no decorrer do curso e questionários obtidos a partir de entrevistas com os mesmos não foram considerados para esse estudo.

\section{Resultados e Discussão}

Os fatores que, segundo dados da literatura científica, podem influenciar na questão da permanência de discentes em cursos de nível superior na modalidade a distância e que, desde a matrícula, estão disponibilizados na plataforma de registro acadêmico do IFPB - SUAP, foram selecionados e operacionalizados em 08 (oito) variáveis nesta pesquisa. Uma variável representada neste trabalho como dependente (situação) e sete variáveis independentes, sendo duas variáveis métricas (Ano de Nascimento e Ano de Conclusão do Ensino Médio) e cinco variáveis categóricas conforme o Quadro 2.

Quadro 2. Variáveis descritas utilizadas nesta pesquisa.

\begin{tabular}{|l|l|l|}
\hline Variável & Descrição & Valores \\
\hline Situação & $\begin{array}{l}\text { Situação do discente referente a sua matrícula } \\
\text { no curso na data de realização da pesquisa. }\end{array}$ & $\begin{array}{l}\text { Cancelado, Cancelamento Compulsório, } \\
\text { Evasão, Matriculado, Trancado } \\
\text { Voluntariamente }\end{array}$ \\
\hline $\begin{array}{l}\text { Ano de } \\
\text { Nascimento }\end{array}$ & Ano de nascimento do discente. & <Valor em ano> \\
\hline Estado Civil & $\begin{array}{l}\text { Situação de um cidadão em relação ao } \\
\text { matrimônio. }\end{array}$ & $\begin{array}{l}\text { Casado, Divorciado, Solteiro, União } \\
\text { Estável }\end{array}$ \\
\hline Sexo & Sexo do discente. & Masculino ou Feminino \\
\hline Etnia & Cor ou raça quando declarada pelos discentes. & $\begin{array}{l}\text { Amarela, Branca, Pardo, Preta, Não } \\
\text { Declarada }\end{array}$ \\
\hline $\begin{array}{l}\text { Instituição de } \\
\text { Ensino de Origem } \\
\text { do Ensino Médio }\end{array}$ & $\begin{array}{l}\text { Natureza do estabelecimento educacional de } \\
\text { origem do discente. }\end{array}$ & $\begin{array}{l}\text { Privada, Pública } \\
\text { discente. }\end{array}$ \\
\hline Zona & $\begin{array}{l}\text { Característica do espaço geográfico da } \\
\text { resia do discente. }\end{array}$ & Rural, Urbana \\
\hline
\end{tabular}

Fonte: Elaborado pelos autores. 
Para nosso estudo, adotaremos as categorias cancelado, cancelamento compulsório, evasão e trancado voluntariamente como os casos de não êxito. Já os casos definidos como matriculado foram registrados como de êxito. Cabe ressaltar também que a variável etnia pode receber o valor de não declarada. Para efeitos de categorização, embora os registros de ano de nascimento e ano de conclusão do ensino médio fossem originalmente valores numéricos, estabelecemos também categorias que abrangem uma faixa de cinco anos para sintetizar as análises.

Tabela 1. Estatística descritiva do grupo de estudo.

\begin{tabular}{|c|c|c|c|}
\hline Variável & Valores obtidos & $\mathrm{F}$ & $\%$ \\
\hline \multirow[t]{5}{*}{ Situação } & Cancelado & 34 & 14,91 \\
\hline & Cancelamento Compulsório & 1 & 0,44 \\
\hline & Evasão & 111 & 48,68 \\
\hline & Matriculado & 79 & 34,65 \\
\hline & Trancado Voluntariamente & 3 & 1,32 \\
\hline \multirow[t]{9}{*}{ Ano de Nascimento } & $1960-1964$ & 1 & 0,44 \\
\hline & 1965-1969 & 7 & 3,07 \\
\hline & $1970-1974$ & 5 & 2,19 \\
\hline & $1975-1979$ & 26 & 11,40 \\
\hline & $1980-1984$ & 36 & 15,79 \\
\hline & $1985-1989$ & 48 & 21,05 \\
\hline & 1990-1994 & 50 & 21,93 \\
\hline & 1995-1999 & 42 & 18,42 \\
\hline & $2000-2003$ & 13 & 5,70 \\
\hline \multirow[t]{4}{*}{ Estado Civil } & Casado & 80 & 35,09 \\
\hline & Divorciado & 7 & 3,07 \\
\hline & Solteiro & 137 & 60,09 \\
\hline & União Estável & 4 & 1,75 \\
\hline \multirow[t]{2}{*}{ Sexo } & Feminino & 160 & 70,18 \\
\hline & Masculino & 68 & 29,82 \\
\hline \multirow[t]{5}{*}{ Etnia } & Amarela & 3 & 1,32 \\
\hline & Branca & 63 & 27,63 \\
\hline & Pardo & 135 & 59,21 \\
\hline & Preta & 17 & 7,46 \\
\hline & Não Declarada & 10 & 4,39 \\
\hline \multirow[t]{2}{*}{ IE de Origem } & Privada & 30 & 13,16 \\
\hline & Pública & 198 & 86,84 \\
\hline \multirow[t]{8}{*}{ Ano de Conclusão do EM } & 1980-1984 & 1 & 0,44 \\
\hline & $1985-1989$ & 4 & 1,75 \\
\hline & 1990-1994 & 4 & 1,75 \\
\hline & 1995-1999 & 21 & 9,21 \\
\hline & 2000-2004 & 37 & 16,23 \\
\hline & 2005-2009 & 49 & 21,49 \\
\hline & $2010-2014$ & 71 & 31,14 \\
\hline & $2015-2019$ & 41 & 17,98 \\
\hline \multirow[t]{2}{*}{ Zona } & Rural & 31 & 13,60 \\
\hline & Urbana & 197 & 86,40 \\
\hline
\end{tabular}

Fonte: Elaborado pelos autores.

Podemos observar, dos dados acima levantados, que temos um total de 34,65\% de alunos ainda matriculados do total de alunos que inicialmente entrou no curso. Por conseguinte, temos um valor atribuído a cancelado, cancelamento compulsório, evasão e trancado voluntariamente totalizado em $65,35 \%$. Um pouco mais de um terço dos alunos continua matriculado no curso findo o segundo ano de curso. Cabe verificar que a EEP do referido curso tem um índice bastante elevado chegando praticamente a dois terços de evasão dos ingressantes. Fato esse já verificado em Branco, Conte e Habowski (2020), em que alguns alunos se matriculam e nem chegam a iniciar o curso, principalmente por não entenderem a metodologia de 
ensino adotada nos cursos e/ou por enfrentarem dificuldades na participação das atividades propostas.

Em relação ao ano de nascimento, verificamos que a maior parte dos alunos nasceu entre 1990 e 1994, com idades entre 25 e 29 anos usando como referência seu ingresso no curso superior. O mais habitual é que estudantes iniciem a graduação após finalizar o ensino médio, fato que geralmente acontece entre 16 e 19 anos. Há uma meta, inclusive no Plano Nacional de Educação (PNE) 2014-2024 - Lei n 13.005/2014 (BRASIL, 2014), que pretende elevar a taxa bruta de matrícula na educação superior para 50\% e a taxa líquida para 33\% da população de 18 a 24 anos.

Quando realizamos uma comparação com o Exame Nacional do Ensino Médio (Enem) de 2020, em relação à faixa etária, mais da metade dos participantes tem até 20 anos de idade (BRASIL, 2020). No caso dos ingressantes no curso de EaD em tela, essa taxa reduz para apenas 7,45\% dos ingressantes com até 20 anos de idade.

A correlação entre o ano de nascimento e o ano de conclusão do Ensino Médio é de aproximadamente 0,763904. Portanto verificamos, como esperado, que existe uma correlação forte entre essas duas variáveis de escala métrica. Importante frisar que, a priori, sabíamos que encontraríamos uma correlação positiva para essas variáveis. Todavia, era interessante pontuar se essa correlação era muito forte, forte ou apenas moderada.

Interessante pontual também que os desvios padrão referentes ao ano de nascimento e ao ano de conclusão do Ensino Médio, expressão do grau de dispersão dos referidos conjuntos de dados em relação à média, é bastante elevado. Percebe-se, portanto, conforme Tabela 2, que há uma faixa etária extensa dos ingressantes do curso relacionadas a essas variáveis, com altas taxas de desvio padrão.

Tabela 2. Medidas estatísticas para as variáveis métricas.

\begin{tabular}{lrrrc}
\hline Variável & Menor score & Maior score & Média & Desvio padrão \\
\hline Ano de Nascimento & 1960 & 2003 & 1988 & 8,53 \\
\hline Ano de Conclusão do EM & 1980 & 2019 & 2008 & 7,22 \\
\hline
\end{tabular}

Fonte: Elaborado pelos autores.

No que tange ao estado civil, temos maior representação entre os solteiros com mais da metade dos inscritos (60,09\%), seguido pelos casados com aproximadamente 35,09\%. Temos que considerar que a representação dos alunos casados pesquisados, embora não seja a maior representação, é muito representativa com mais de um terço dos sujeitos. Naturalmente é aceitável o entendimento que há uma forte relação entre o estado civil e o fato de possuir emprego, uma vez que parte da população estudada é a principal ou a única responsável pelos meios de subsistência da família.

Temos uma população em sua maioria declarada parda $(59,21 \%)$, seguida pela etnia branca $(27,63 \%)$. No campo jurídico, a lei $\mathrm{n}^{\mathrm{o}}$ 12.711/2012 (BRASIL, 2012), que dispõe sobre o ingresso nas universidades federais e nas instituições federais de ensino técnico de nível médio, tem praticamente uma década de existência. Essa norma legal estabelece que todas as instituições alcançadas pelo dispositivo legal devem designar metade de suas vagas para egressos de escola pública, entre as quais 50\% devem ser para pessoas de baixa renda. Ainda segundo Silva (2020), nas vagas reservadas, também deve-se considerar cotas para candidatos pretos, pardos, indígenas e pessoas com deficiência - estas últimas instituídas pela lei $\mathrm{n}^{\circ}$ 13.409/2016 (BRASIL, 2012), que dispõe sobre a reserva de vagas para pessoas com deficiência nos cursos técnico de nível médio e superior das instituições federais de ensino.

No tocante entre tipo de zona de residência (urbana e rural), em 2010, o censo demográfico (IBGE, 2012) contabilizou aproximadamente 24 milhões de jovens entre 18 e 24 anos com distribuição no território semelhante à população total, sendo $85 \%$ residentes em zonas urbanas. Esse dado é corroborado quando observamos que há $86,40 \%$ de alunos da zona urbana 
matriculados no referido curso. Como pontua (Vasconcelos, 2016), a residência em área urbana favorece em muito a escolarização do jovem e seu acesso ao ensino superior. Principalmente no que concerne ao acesso ao curso superior na modalidade à distância.

Quando observamos os dados especificando a situação do aluno, podemos observar o descrito abaixo.

Tabela 3. Situação de matrícula por sexo dos alunos.

\begin{tabular}{|c|c|c|c|}
\hline Situação de Matrícula & Sexo & $\mathrm{N}$ & $\%$ \\
\hline \multirow[t]{2}{*}{ Matriculados } & Feminino & 60 & 75,95 \\
\hline & Masculino & 19 & 24,05 \\
\hline (Cancelado, Cancelamento & Feminino & 100 & 67,11 \\
\hline Compulsório, Evasão, Trancado Voluntariamente) & Masculino & 49 & 32,89 \\
\hline
\end{tabular}

Fonte: Elaborado pelos autores.

Dos alunos atuais que permanecem matriculados, temos aproximadamente $76 \%$ de alunos do sexo feminino e $24 \%$ de alunos do sexo masculino. Dos alunos não matriculados, observamos duas grandes categorias (cancelados e evasão). Contato alunos evadidos com praticamente $75 \%$ do total das não matrículas, conforme Tabela 4.

Outro ponto a destacar é que, percentualmente, o valor dos alunos do sexo masculino que cancelaram $(41,18 \%)$ e se evadiram do curso $(30,63 \%)$ é maior do que o valor da amostra completa dos alunos do sexo masculino ingressantes $(29,82 \%)$.

Tabela 4. Sexo dos discentes por situação de não matriculados.

\begin{tabular}{lllll}
\hline Não matriculados & Sexo & N & $\%$ & $\begin{array}{c}\text { \% total de não } \\
\text { matriculados }\end{array}$ \\
\hline Cancelados & Feminino & 20 & 58,82 & 22,82 \\
& Masculino & 14 & 41,18 & \\
\hline Cancelamento Compulsório & Feminino & 1 & 100 & 0,67 \\
& Masculino & 0 & 0 & \\
\hline Evasão & Feminino & 77 & 69,37 & 74,50 \\
& Masculino & 34 & 30,63 & \\
\hline Trancado Voluntariamente & Feminino & 2 & 66,67 & 2,01 \\
& Masculino & 1 & 33,33 & \\
\hline
\end{tabular}

Fonte: Elaborado pelos autores.

Interessante pontuar que quando nos referimos a zona de residência, levando em consideração a situação de matrícula, não observamos nos dados diferença significativa entre a amostra completa analisada e a parte referente aos discentes que permanecem ou não matriculados. Fato este que nos leva a crer que não ouve EEP expressiva no tocante a zona de residência do estudante. 
Tabela 5. Zona de residência estudantil por situação de matrícula.

\begin{tabular}{llrr}
\hline Situação de Matrícula & Residência & N & \% \\
\hline Matriculados & Rural & 11 & 13,92 \\
& Urbana & 68 & 86,08 \\
\hline Não matriculados & Rural & 20 & 13,42 \\
& Urbana & 129 & 86,58 \\
\hline
\end{tabular}

Fonte: Elaborado pelos autores.

Tabela 6. Municípios de residência dos estudantes.

\begin{tabular}{lc}
\hline Cidade - Estado & Ocorrências \\
\hline João Pessoa - PB & 39 \\
Campina Grande - PB & 24 \\
Sousa - PB & 17 \\
Barra de Santa Rosa - PB* & 13 \\
Cajazeiras - PB & 7 \\
Cuité - PB* & 7 \\
Picuí - PB* & 7 \\
Patos - PB & 6 \\
Ingá - PB* & 5 \\
Baraúna - PB* & 4 \\
Esperança - PB & 4 \\
Poço Dantas - PB* & 4 \\
Santa Rita - PB & 4 \\
Alagoa Grande - PB & 3 \\
Araruna - PB* & 3 \\
Carnaúba dos Dantas - RN & 3 \\
Lastro - PB & 3 \\
Solânea - PB* & 3 \\
Uiraúna - PB* & 3 \\
\hline
\end{tabular}

*Municípios do estado da Paraíba que não se encontram no ranking das vinte cidades mais populosas do estado da Paraíba segundo o IBGE. Fonte: Elaborado pelos autores.

Não aparecem na tabela acima dos municípios com maiores números de discentes residentes, algumas das cidades mais populosas na Paraíba, conforme o Censo Demográfico 2010 (IBGE, 2012). Estão ausentes da tabela os municípios de Bayeux, Cabedelo, Guarabira, Sapé, Mamanguape, Queimadas, Pombal, São Bento, Monteiro, Catolé do Rocha e Pedras de Fogo. Fato este explicado, também, porque não há pólos EaD do IFPB em nenhum desses locais. Ou mesmo, pela proximidade dessas cidades a regiões onde o instituto já possui os referidos pólos de ensino à distância. Cabe ressaltar apenas a presença do município de Barra de Santa Rosa que apresenta 13 alunos e ocupa a $4^{a}$ colocação dentre os municípios com maior número de discentes vinculados ao curso. Esse município aparece apenas da $57^{\mathrm{a}}$ posição em número de habitantes, conforme o Censo Demográfico 2010 (IBGE, 2012).

Cabe pontuar que uma das estratégias da meta relacionada a elevação da taxa bruta de matrícula na educação superior do Plano Nacional de Educação (PNE) 2014-2024 - Lei nº 13.005/2014 (BRASIL, 2014) é a ampliação da oferta de vagas, por meio da expansão e interiorização da rede federal de educação superior, considerando a densidade populacional, a oferta de vagas públicas em relação à população na idade de referência e observadas as características regionais das micro e mesorregiões. Quando observamos a totalidade dos municípios de residência desses discentes, 72 (setenta e duas) cidades incluindo municípios de outros estados da federação, pode-se entender que a EaD promovida pelo IFPB vem, para além do 
simples crescimento em número de matrículas, cumprindo seu papel de interiorização da educação superior.

\section{Conclusão}

A EEP é um fenômeno acadêmico muito vinculado a modalidade EaD. Os atores responsáveis desta modalidade de ensino enfrentam inúmeros desafios na tentativa de imprimir fazeres e práticas capazes de estimular o acesso, a permanência e o sucesso no processo de ensino-aprendizagem de seus alunos. Para que a instituição educativa como um todo possa adotar medidas capazes de minimizar os processos de evasão precoce é muito importante se conhecer as causas que motivaram essa ocorrência e suas diferentes nuances.

Definir políticas de retenção, analisar as probabilidades individuais de abandono desde o ingresso do aluno e redefinir práticas pedagógicas que possam ser mais inclusivas e colaborativas no sistema de educação à distância são apontamentos que podem direcionar os atores educacionais, gestores e professores, a estabelecer condutas que reverberem na permanência desse aluno na escola.

A quantificação desses riscos de evasão pode, portanto, ser útil na alocação de recursos pedagógicos e administrativos de forma eficiente.

\section{Agradecimentos}

Este trabalho foi apoiado pela Pró-reitora de Pesquisa, Inovação e Pós-Graduação do Instituto Federal de Educação, Ciência e Tecnologia da Paraíba, por meio de concessão de bolsa de pesquisa no âmbito do edital nº 03/2020 - PIDETEC EaD - IFPB.

\section{Referências}

Bittencourt, I. M. \& Mercado, L. P. L. (2014). Evasão nos cursos na modalidade de educação a distância: estudo de caso do Curso Piloto de Administração da UFAL/UAB. Ensaio: aval.pol.públ.Educ., 22 (83), 465-504.

Braga, M. M., Peixoto, M. do C. L. \& Bogutchi, T. F. (2003). A evasão no ensino superior brasileiro: o caso da UFMG. Avaliação (Campinas), 8(1), 161-189.

Branco, L. S. A., Conte, E. \& Habowski, A. C. (2020). Evasão na educação a distância: pontos e contrapontos à problemática. Avaliação (Campinas), 25(1), 132-154.

Brasil. Diplomação, retenção e evasão nos cursos de graduação em instituições de ensino superior públicas. Relatório da comissão especial de estudos sobre evasão nas universidades públicas brasileiras. Brasília: ANDIFES/ABRUEM/SESu/MEC, 1996.

Brasil. Ministério da Educação. 5,8 milhões estão inscritos para fazer o Enem 2020. Portal do Governo Federal, Brasília, DF, 23 de jun. de 2020. Disponível em: <https://www.gov.br/mec/pt-br/assuntos/noticias/5-8-milhoes-estao-inscritos-para-fazer-o-enem-2020>.

Carneiro, T., Silva, M. \& Bizarria, F. (2015). Fatores que afetam a permanência dos discentes em cursos de graduação a distância: um estudo na universidade da integração internacional da lusofonia afro-brasileira. Gestão e Sociedade, 8(20), 651-669.

Carvalho, P. S. de A., Almeida, E. A. \& Cavalcanti, M. da C. M. (2018). Análise da evasão na Educação a Distância: um estudo no curso de bacharelado em Administração Pública do IFPB/UAB. Principia, 1(41), 139-151.

Cornelio, R. A., Vasconcelos, F. C. W. \& Goulart, I. B. (2016). Educação a Distância: Uma Análise Estatística dos Fatores Relacionados à Evasão e à Permanência. Revista GUAL, 9(4), 26-44.

Habowski, A. C., Branco, L. S. A. \& Conte, E. (2020). Evasão na EAD: perspectivas de prevenção. Perspectiva, 38(3), 1-20.

Instituto Brasileiro de Geografia e Estatística - IBGE. Censo Demográfico 2010. Resultados gerais da amostra. Rio de Janeiro: IBGE, 2012.

Instituto Nacional de Estudos e Pesquisas Educacionais Anísio Teixeira - INEP. Censo da Educação Superior 2017: divulgação dos principais resultados Brasília, DF, 2018. Disponível em: http://portal.mec.gov.br/index.php?option=com_docman\&view=download\&alias=97041-apresentac-a-o-censo-superior-u1timo\&Itemid=30192.

Queiroga, E., Lopes, J. L., Araújo, R. M. de \& Cechinel, C. (2018). Modelo de predição da evasão de estudantes em cursos técnicos a distância a partir da contagem de interações. Revista Thema, 15(2), 425-438. 
Research, Society and Development, v. 10, n. 7, e31510717230, 2021

(CC BY 4.0) | ISSN 2525-3409 | DOI: http://dx.doi.org/10.33448/rsd-v10i7.17230

Kemper, L., Vorhoff, G. \& Wigger, B. U. (2020). Predicting student dropout: A machine learning approach. European Journal of Higher Education, 10(1), $28-47$.

Koche, J. C. (2011). Fundamentos de metodologia científica. Petrópolis: Vozes.

Lima, M. A. M. et al. (2020). Algoritmos de avaliação: modelagem e aplicação no estudo da evasão discente. Estud. Aval. Educ., 31(77), 318-340.

Ludke, M. \& Andre, M. E. D. A. (2013). Pesquisas em educação: uma abordagem qualitativa. São Paulo: E.P.U.

Melo, J. R. F. de. \& Melo, E. S. N. (2021). Abstraction and Computational Thinking: Possibilities as from the New Brazilian National Common Curricular Basis. International Journal of Advanced Engineering Research and Science, 8(1), 85-90.

Prestes, E. M. da T. \& Fialho, M. G. D. (2018). Evasão na educação superior e gestão institucional: o caso da Universidade Federal da Paraíba. Ensaio: aval.pol.públ.Educ., 26(100), 869-889.

Silva, T. D. (2020). TD 2569 - Ação afirmativa e população negra na educação superior: acesso e perfil discente. Instituto de Pesquisa Econômica Aplicada. Rio de Janeiro: Ipea.

Tinto, V. (1975). Dropout from higher education: a theoretical synthesis of recent research. Review of Educational Research, 45(1), 89-125.

Vasconcelos, A. M. N. Juventude e ensino superior no Brasil. In: Dwyer, T. et al. (org.). (2016). Jovens universitários em um mundo em transformação: uma pesquisa sino-brasileira. Brasília: Ipea; Pequim: SSAP,125-137. 